\title{
A prospective observational study with dose volume parameters predicting rectosigmoidoscopic findings and late rectosigmoid bleeding in patients with uterine cervical cancer treated by definitive radiotherapy
}

Tae Hyun Kim, Joo-Young Kim, Dae Kyung Sohn, Yeon-Joo Kim, Yoon-Seok Lee, Sung Ho Moon, Sang Soo Kim and Dae Yong Kim

\begin{abstract}
Purpose: We assessed the value of dose-volumetric parameters predicting rectosigmoid mucosal changes (RMC) and late rectosigmoid complications (LRC).

Methods: Between January 2004 and February 2006, 77 patients with stage IB-IIIB cervical cancer underwent external beam radiotherapy and computed tomography (CT)-based intracavitary irradiation. Total dose to the rectal point and several dose-volumetric parameters for rectosigmoid colon $\left(D_{20 c c,}, D_{15 c c,}, D_{10 c c,}, D_{5 c c}, D_{2 c c}, D_{1 c c,}\right.$ and $D_{0.1 c c}$, defined as the minimal doses received by the highest irradiated volumes of 20, 15, 10, 5, 2, 1, and $0.1 \mathrm{cc}$, respectively), were calculated using the equivalent dose in $2 \mathrm{~Gy}$ fractions $\left(\alpha / \beta=3, G y_{3}\right)$. The RMC and LRC were graded by rectosigmoidoscopy and Radiation Therapy Oncology Group criteria every 6 months, respectively.

Results: Of 77 patients, 27 (35.1\%) patients developed RMC $\geq$ score 3 and 22 (28.6\%) patients developed LRC $\geq$ grade 2 . There was a positive correlation between RMC score and LRC grade $(r=0.728, p<0.001)$. In multivariate analyses, $D_{5 c c}$ among the dose-volumetric parameters, was significant parameter for the risks of RMC $\geq$ score 3 and $L R C \geq$ grade $2(p<0.05)$.
\end{abstract}

Conclusions: $\mathrm{D}_{5 \mathrm{cc}}$ may be a more reliable estimate than other dose-volumetric parameters for predicting the risk of $R M C \geq$ score 3 and $L R C \geq$ grade 2 in CT-based brachytherapy.

Keywords: Dose-volumetric parameters, Rectosigmoid mucosal change, Late rectosigmoid complication, Uterine cervical cancer

\section{Introduction}

Traditionally, the rectal point, defined by the International Commission on Radiation Units and Measurements Report 38 (ICRU 38), has been used as a reference point to represent the rectal dose in brachytherapy of cervical cancer. However, a single point dose using two-dimensional orthogonal radiographs does not account for the exact tumor and normal tissue anatomy and is not accurate enough in

\footnotetext{
* Correspondence: jooyoungcasa@ncc.re.kr

Research Institute and Hospital, National Cancer Center, Goyang, Gyeonggi, South Korea
}

estimating the risk of late rectal complication (LRC). Recently, with the introduction of three-dimensional (3D) treatment planning using computed tomography (CT) and magnetic resonance imaging (MRI), several dosevolumetric parameters, including $\mathrm{D}_{2 \mathrm{cc}}, \mathrm{D}_{1 \mathrm{cc}}$, and $\mathrm{D}_{0.1 \mathrm{cc}}$ (the minimal doses received by the highest irradiated $2 \mathrm{cc}$, $1 \mathrm{cc}$ and $0.1 \mathrm{cc}$ volumes of the rectum and sigmoid colon, respectively) are more frequently used in optimizing the treatment [1-6].

We have been using CT-based brachytherapy since 2004 before we moved into MRI-based brachytherapy in 2008 [7]. A prospective observational study to assess the value 
of dose-volumetric parameters predicting rectosigmoid mucosal changes (RMCs) using serial rectosigmoidoscopy was started for the patients treated with 3D CT-based brachytherapy. A preliminary result showed that the aforementioned dose-volumetric parameters were significantly associated with RMC on rectosigmoidoscopy at 12 months [8]. The current report is our final result of the study showing the correlations among RMC, LRC, and dosevolumetric parameters.

\section{Methods}

\section{Patients}

Between January 2004 and February 2006, a total of 80 patients who were treated with definitive radiotherapy (RT) were enrolled in this study. The eligibility criteria were described previously [8]. The study consisted of a specific interview about the rectal symptom and one rectosigmoidoscopy every 6 months for 2 years. The study was approved by our institutional review board and all patients provided written informed consent. Of 80 patients, three patients who died within 24 months due to local and/or distant disease progression after RT were excluded from analysis; the remaining 77 patients were analyzed. Prior to RT, all patients underwent a pelvic examination, chest radiography, cystoscopy, rectosigmoidoscopy, and pelvic MRI with/without CT. Patient characteristics are summarized in Table 1.

\section{Treatment}

RT consisted of a combination of external beam radiation therapy (EBRT) and high dose rate ICR (HDR-ICR). The details of the RT techniques have been described $[7,8]$. In brief, EBRT was delivered by a linear accelerator with a 15-MV X-ray using the 4-field box technique in daily fractions of 1.8-2 Gy, 5 days/week, with a total parametrial dose of 45-66 Gy (median, 54 Gy). A $4 \mathrm{~cm}$ width midline shielding was placed at 36 Gy in 4 elderly patients with stage Ib1 diseases, at $39.6 \mathrm{~Gy}$ in one patient with Stage IIA, and at 45 Gy in 46 patients with stage Ib1 to IIB. Whole pelvis was treated up to 50.4 Gy for the rest of the patients without midline block. HDR-ICR was delivered in 3.3-5 Gy/fraction twice a week up to a median dose of 29 Gy (range, 20-35 Gy) prescribed to the point A using a ${ }^{192}$ Ir remotely controlled afterloading system. Sixty-six patients received concurrent chemotherapy as follows: cisplatin (5 cycles of weekly intravenous injection at $40 \mathrm{mg} / \mathrm{m}^{2} /$ day) in 65 patients and cisplatin plus 5fluorouracil (3 cycles of intravenous injection of cisplatin at $50 \mathrm{mg} / \mathrm{m}^{2} /$ day, day 1 , and $1000 \mathrm{mg} / \mathrm{m}^{2} /$ day of 5 -fluorouracil, days $1-5$, followed by 14 days rest at each cycle) in one patient.

The imaging, contouring, and planning details were described previously [8]. In brief, a series of transverse images of the pelvic region were acquired using a CT simulator with the applicators in place. The target volume and organs at risk (OARs) were delineated by radiation oncologists. All patients were examined by a baseline MRI of the pelvis and an additional MRI prior to ICR simulation to aid contouring of clinical target volume (CTV). CTV included the whole cervix plus any residual parametrial disease and was in accordance with high-risk CTV defined by the Gynecologic Groupe Européen de Curiethérapie and the European Society for Therapeutic Radiology and Oncology (GEC-ESTRO) recommendations [6]. Outer organ contours were delineated for the bladder and rectosigmoid colon; the rectum was defined from the anorectal junction to the rectosigmoid flexure. Treatment planning was optimized from January 2005 with the goal that the dose receiving $\geq 90 \%$ of CTV must be greater than the prescribed dose and that the volume treated with at least the prescribed dose must be $\geq 90 \%$. The rectum and sigmoid colon should each receive $<90 \%$ of the prescribed dose at any point.

\section{Determination of dose-volume parameters}

Cumulative DVHs for each OAR were computed and the $D_{20 c c}, D_{15 c c}, D_{10 c c}, D_{5 c c}, D_{2 c c}, D_{1 c c}$, and $D_{0.1 c c}$ of each OAR (the minimal doses received by the highest irradiated $20 \mathrm{cc}, 15 \mathrm{cc}, 10 \mathrm{cc}, 5 \mathrm{cc}, 2 \mathrm{cc}, 1 \mathrm{cc}$, and $0.1 \mathrm{cc}$ volumes of OAR, respectively) were determined. The doses to point $A\left(D_{\text {point }} \mathrm{A}\right)$ and ICRU reference points for the bladder and rectum $\left(D_{B P}\right.$ and $D_{R B}$, respectively) were also calculated. The total dose (EBRT plus ICR) was calculated as the biologically equivalent dose in 2-Gy fractions (EQD2) using the linear quadratic model [9]. The equation used to calculate the total EQD2 was:

$$
\begin{aligned}
\mathrm{EQD} 2_{\text {total }}= & \mathrm{EQD} 2_{\mathrm{EBRT}}+\mathrm{EQD} 2_{\mathrm{ICR}} \\
= & \operatorname{Nd}[(d+\alpha / \beta) /(2+\alpha / \beta)] \\
& +N_{B} d_{B}\left[\left(d_{B}+\alpha / \beta\right) /(2+\alpha / \beta)\right]
\end{aligned}
$$

where $\mathrm{Nd}$ is the total dose of EBRT (before central shielding), $d$ is the fractional dose of EBRT, $N_{B} d_{B}$ is the total dose of HDR-ICR, and $d_{B}$ is the fractional dose of HDR-ICR to the CTV and OARs. The $\alpha / \beta$ values of 10 and 3 were applied for the CTV and OARs, respectively.

\section{Evaluation of LRCs and follow-up}

Patient follow-up was performed every 3 months in the first 2 years following RT, every 4 months in the third year, then every 6 months for up to 5 years, and yearly thereafter. Apart from the routine evaluation of the status of cervical cancer [8], the follow-up included a specific interview evaluating the symptom complex related to the rectal morbidity (i.e., bleeding) and a flexible rectosigmoidoscopy (CF-Q240 or CF-H260; Olympus Optical Co., Tokyo, Japan) examination at every 6 months for the first 2 years. In total, rectosigmoidoscopy was 
Table 1 Associations of clinical and dose-volumetric parameters parameters with the rectosigmoid mucosal change score (RMC) $\geq 3$ and late rectal complication (LRC) grade $\geq 2$

\begin{tabular}{|c|c|c|c|c|c|c|c|c|}
\hline & & \multirow{2}{*}{$\begin{array}{l}\text { Total } \\
\text { Patients, n (\%) }\end{array}$} & \multicolumn{2}{|l|}{ RMC } & \multirow[b]{2}{*}{$p$-value } & \multicolumn{2}{|l|}{$\underline{\text { LRC }}$} & \multirow[b]{2}{*}{$p$-value } \\
\hline & & & Score $<3, \mathrm{n}(\%)$ & $\geq$ Score 3, n (\%) & & Grade $<2, \mathrm{n}(\%)$ & Grade $\geq 3, \mathrm{n}(\%)$ & \\
\hline \multirow[t]{2}{*}{ Age (years) } & $\leq 60$ & $50(64.9)$ & $35(70)$ & $15(30)$ & $0.222^{*}$ & $38(76)$ & $12(24)$ & $0.292^{*}$ \\
\hline & $>60$ & $27(35.1)$ & 15 (55.6) & $12(44.4)$ & & $17(63)$ & $10(37)$ & \\
\hline \multirow[t]{2}{*}{ Histology } & Squamous cell carcinoma & $70(90.9)$ & $44(62.9)$ & $26(37.1)$ & $0.411^{*}$ & $49(70)$ & $21(30)$ & $0.666^{*}$ \\
\hline & Adenocarcinoma & $7(9.1)$ & $6(85.7)$ & $1(14.3)$ & & $6(85.7)$ & $1(14.3)$ & \\
\hline \multirow[t]{2}{*}{ Tumor size $(\mathrm{cm})$} & $\leq 4$ & $41(53.2)$ & $29(70.7)$ & $12(29.3)$ & $0.339^{*}$ & $32(78)$ & $9(22)$ & $0.210^{*}$ \\
\hline & $>4$ & $36(46.8)$ & $21(58.3)$ & $15(41.7)$ & & $23(63.9)$ & $13(36.1)$ & \\
\hline \multirow[t]{2}{*}{ Stage } & $\mid \mathrm{B}-\| \mathrm{A}$ & $32(41.6)$ & $27(84.4)$ & $5(15.6)$ & $0.003^{*}$ & $29(90.6)$ & $3(9.4)$ & $0.002^{*}$ \\
\hline & $\|B-\| B$ & $45(58.4)$ & $23(51.1)$ & $22(48.9)$ & & $26(57.8)$ & $19(42.2)$ & \\
\hline \multirow[t]{2}{*}{ Concurrent chemotherapy } & Yes & $66(85.7)$ & $43(65.2)$ & $23(34.8)$ & $1.000^{*}$ & $48(72.7)$ & $18(27.3)$ & $0.719^{*}$ \\
\hline & No & $11(14.3)$ & $7(63.6)$ & $4(36.4)$ & & $7(63.6)$ & $4(36.4)$ & \\
\hline \multirow[t]{2}{*}{ Diabetes Mellitus } & Yes & $6(7.8)$ & $5(83.3)$ & $1(16.7)$ & $0.417^{*}$ & $5(83.3)$ & $1(16.7)$ & $0.668^{*}$ \\
\hline & No & 71 (92.2) & 45 (16.7) & $26(44.4)$ & & $50(70.4)$ & 21 (29.6) & \\
\hline \multirow[t]{2}{*}{ Hypertension } & Yes & $20(26)$ & $10(50)$ & $10(50)$ & $0.172^{*}$ & $12(60)$ & $8(40)$ & $0.251^{*}$ \\
\hline & No & $57(74)$ & $40(70.2)$ & 17 (29.8) & & $43(75.4)$ & $14(24.5)$ & \\
\hline \multirow[t]{2}{*}{ Smoking } & Yes & $12(15.6)$ & $10(83.3)$ & $2(16.7)$ & $0.491^{*}$ & $9(75)$ & $3(25)$ & $0.524^{*}$ \\
\hline & No & $65(84.4)$ & $45(69.2)$ & 20 (30.8) & & $41(63.1)$ & 24 (36.9) & \\
\hline$D_{\mathrm{RP}}\left(\mathrm{Gy}_{3}\right)$ & $(\mu \pm \sigma)$ & & $69.1 \pm 12.3$ & $75.4 \pm 18.3$ & $0.124^{\dagger}$ & $69.2 \pm 11.9$ & $76.7 \pm 20.0$ & $0.120^{\dagger}$ \\
\hline$D_{0.1 c c}\left(G y_{3}\right)$ & $(\mu \pm \sigma)$ & & $87.2 \pm 15.6$ & $101.7 \pm 26.7$ & $0.014^{+}$ & $87.9 \pm 15.9$ & $103.1 \pm 28.4$ & $0.026^{\dagger}$ \\
\hline $\mathrm{D}_{1 \mathrm{cc}}\left(\mathrm{Gy}_{3}\right)$ & $(\mu \pm \sigma)$ & & $75.1 \pm 10.9$ & $85.2 \pm 14.4$ & $0.001^{\dagger}$ & $75.8 \pm 11.1$ & $85.6 \pm 15.2$ & $0.002^{\dagger}$ \\
\hline$D_{2 c c}\left(G y_{3}\right)$ & $(\mu \pm \sigma)$ & & $70.8 \pm 9.8$ & $79.6 \pm 11.5$ & $0.001^{\dagger}$ & $71.5 \pm 9.9$ & $79.9 \pm 12.0$ & $0.002^{\dagger}$ \\
\hline$D_{5 c c}\left(G y_{3}\right)$ & $(\mu \pm \sigma)$ & & $64.6 \pm 8.2$ & $72.0 \pm 8.4$ & $<0.001^{\dagger}$ & $65.2 \pm 8.3$ & $72.2 \pm 8.8$ & $0.002^{\dagger}$ \\
\hline $\mathrm{D}_{10 \mathrm{cc}}\left(\mathrm{Gy} \mathrm{y}_{3}\right)$ & $(\mu \pm \sigma)$ & & $59.5 \pm 6.4$ & $63.4 \pm 6.0$ & $0.011^{\dagger}$ & $60.1 \pm 6.7$ & $62.7 \pm 5.8$ & $0.107^{\dagger}$ \\
\hline $\mathrm{D}_{15 \mathrm{cc}}\left(\mathrm{Gy}_{3}\right)$ & $(\mu \pm \sigma)$ & & $56.3 \pm 5.8$ & $60.2 \pm 5.0$ & $0.004^{+}$ & $56.8 \pm 5.8$ & $59.9 \pm 5.3$ & $0.034^{\dagger}$ \\
\hline $\mathrm{D}_{20 \mathrm{cc}}\left(\mathrm{Gy}_{3}\right)$ & $(\mu \pm \sigma)$ & & $55.4 \pm 5.8$ & $59.1 \pm 4.8$ & $0.006^{\dagger}$ & $55.9 \pm 5.9$ & $58.8 \pm 4.9$ & $0.040^{\dagger}$ \\
\hline
\end{tabular}

Abbreviations: $D_{R P}=$ doses to the reference points for the rectum; $D_{0.1 c c^{\prime}} D_{1 c c^{\prime}} D_{2 c c^{\prime}} D_{5 c c^{\prime}} D_{10 c c^{\prime}} D_{15 c c^{\prime}}$ and $D_{20 c c}=$ minimal doses received by the highest irradiated 0.1, 1, 2, 5, 10, 15, and 20 cc volumes of the rectosigmoid colon, respectively.; $\mu=$ mean; $\sigma=$ standard deviation.

"Fisher's exact test.

${ }^{\dagger}$ Student's $t$-test. 
performed in 49 patients at 6, 12, 18, and 24 months; 12 patients at 6,12 , and 18 months; 9 patients at 6,12 , and 24 months; and 7 patients at 6 and 12 months. For evaluating RMC, we adopted an endoscopic scoring system $[8,10]$ and determined the worst score through the whole wall of the rectosigmoid colon among all serial examinations. LRC was classified according to the Radiation Therapy Oncology Group (RTOG) late radiation morbidity scoring criteria [11].

\section{Statistical analysis}

To analyze dose-volumetric effects, an $\mathrm{RMC} \geq$ score 3 and LRC $\geq$ grade 2 were used as quantal endpoints. Correlations among RMC, LRC, clinical, and dose-volumetric parameters were assessed using Fisher's exact test, Student's $t$-test, and Spearman's and Pearson's correlation coefficient tests, respectively. The overall survival rate was calculated using the Kaplan-Meier method; all time intervals were measured from the first day of RT. Doseresponse relationships influencing the probabilities of $\mathrm{RMC} \geq$ scores $3, \mathrm{LRC} \geq$ grades 2 were analyzed using a logistic regression model. In multivariate analysis, a stepwise logistic regression model was used with all clinical and dose-volumetric parameters to predicting the risks of RMC and LRC. In this procedure, the forward selection of the parameter was processed by the score chi-square test and the backward elimination by the Wald test. All statistical tests were 2-sided and were performed using STATA software (version 9.0, Stata Corp.; College Station, TX). Values of $p<0.05$ indicated statistical significance.

\section{Results}

The median follow-up and 5-year actuarial overall survival rate for all patients were 70.8 months (range, 24.483.9 months) and $90.9 \%$, respectively. The mean CTV for ICR was $48.2 \pm 20.3 \mathrm{~cm}^{3}$ and the volume treated with at least the prescribed dose was $94 \pm 7 \%$. The mean volume of bladder, rectum, and sigmoid colon was 197.9 \pm 104.6 , $79.5 \pm 31.5$, and $30.8 \pm 24.9 \mathrm{~cm}^{3}$, respectively. The mean EQD2 data were comparable with data from other centers (Additional file 1: Table S1), [1,12].

According to the endoscopic scoring criteria, overall distribution of the worst RMC scores through the rectosigmoid colon was score 1 in 30 patients, score 2 in 20 patients, score 3 in 22 patients, score 4 in 1 patient, and score 5 in 4 patients. According to RTOG grade, the overall distribution of LRC grades was grade 0 in 40 patients, grade 1 in 15 patients, grade 2 in 21 patients, grade 3 in 0 patients, grade 4 in 1 patient, and grade 5 in 0 patients. The median interval from the start date of RT to the onset of LRC was 14.6 months (range, 2.6-49.9 months). LRC developed within 24 months in $30(81.1 \%)$ patients. For the rest of the patients $(n=7)$, LRC of RTOG grade $1-2$ developed between the period of $25 \sim 50 \mathrm{Mo}$ ). Figure 1 shows a concordant pattern in observed rates of $\mathrm{RMC} \geq$ score 3 and $L R C \geq$ grade 2 at serial time points and there was a positive correlation between RMC score and LRC grade $(r=0.728, p<0.001)$, (Additional file 1: Table S2).

The results of an univariate analysis evaluating the associations of clinical and dose-volumetric parameters with $\mathrm{RMC} \geq$ score 3 and $\mathrm{LRC} \geq$ grade 2 are summarized in Table 1. Among the clinical parameters, only stage was found to be significantly associated with the risk of RMC $\geq$ score 3 and $L R C \geq$ grade $2(p<0.05)$. The mean values of all dose-volumetric parameters, except in $\mathrm{D}_{0.1 \mathrm{cc}}$, in advanced stage (IIB-IIIB) were significantly higher than those in earlier stage (IB-IIA) ( $\mathrm{D}_{\mathrm{RP}}: 74.3 \pm 15.6$ vs. $67 \pm$ $12.8 \mathrm{~Gy}_{3}, p=0.036 ; \mathrm{D}_{0.1 \mathrm{cc}}: 95.6 \pm 22.7$ vs. $87.6 \pm 18.1 \mathrm{~Gy}_{3}$, $p=0.103 ; \mathrm{D}_{1 \mathrm{cc}}: 81.7 \pm 13.1$ vs. $74.4 \pm 12.1 \mathrm{~Gy}_{3}, p=0.015$; $\mathrm{D}_{2 \mathrm{cc}}: 76.7 \pm 10.7$ vs. $69.9 \pm 10.6 \mathrm{~Gy}_{3}, p=0.007 ; \mathrm{D}_{5 \mathrm{cc}}: 69.8 \pm$ 8.4 vs. $63.5 \pm 8.5 \mathrm{~Gy}_{3}, p=0.002$; $\mathrm{D}_{10 \mathrm{cc}}: 63.2 \pm 5.7$ vs. $57.5 \pm$ $6.2 \mathrm{~Gy}_{3}, p<0.001 ; \mathrm{D}_{15 \mathrm{cc}}: 59.8 \pm 5.1$ vs. $54.8 \pm 5.5 \mathrm{~Gy}_{3}$, $p<0.001$; and $\mathrm{D}_{20 \mathrm{cc}}: 58.8 \pm 5.1$ vs. $53.8 \pm 5.4 \mathrm{~Gy}_{3}, p<0.001$ ). Of the dose-volumetric parameters, the mean values of $D_{0.1 \mathrm{cc}}, \mathrm{D}_{1 \mathrm{cc}}, \mathrm{D}_{2 \mathrm{cc}}, \mathrm{D}_{5 \mathrm{cc}}, \mathrm{D}_{15 \mathrm{cc}}$, and $\mathrm{D}_{20 \mathrm{cc}}$, but not of $\mathrm{D}_{\mathrm{RP}}$ for both RMC and LRC and $D_{10 c c}$ for LRC, in patients who developed an $\mathrm{RMC} \geq$ score 3 or $\mathrm{LRC} \geq$ grade 2 were found to be significantly higher than those in patients who did not $(p<0.05)$ (Table 1). The dose-volumetric parameters were all closely interrelated $\left(\mathrm{D}_{5 \mathrm{cc}}\right.$ vs. $\mathrm{D}_{20 \mathrm{cc}}: r=0.835, p<0.001$; $\mathrm{D}_{5 \mathrm{cc}}$ vs. $\mathrm{D}_{15 \mathrm{cc}}: r=0.837, p<0.001 ; \mathrm{D}_{5 \mathrm{cc}}$ vs. $\mathrm{D}_{10 \mathrm{cc}}: r=0.782$, $p<0.001 ; \mathrm{D}_{5 \mathrm{cc}}$ vs. $\mathrm{D}_{2 \mathrm{cc}}: r=0.974, p<0.001 ; \mathrm{D}_{5 \mathrm{cc}}$ vs. $\mathrm{D}_{1 \mathrm{cc}}$ : $r=0.934, p<0.001 ; \mathrm{D}_{5 \mathrm{cc}}$ vs. $\mathrm{D}_{0.1 \mathrm{cc}}: r=0.795, p<0.001$; and $\mathrm{D}_{5 \mathrm{cc}}$ vs. $\mathrm{D}_{\mathrm{RP}}: r=0.555, p<0.001$, values only for $\mathrm{D}_{5 \mathrm{cc}}$ were described).

The estimated probability values for $\mathrm{RMC} \geq$ score 3 and $\mathrm{LRC} \geq$ grade 2 according to the dose-volumetric

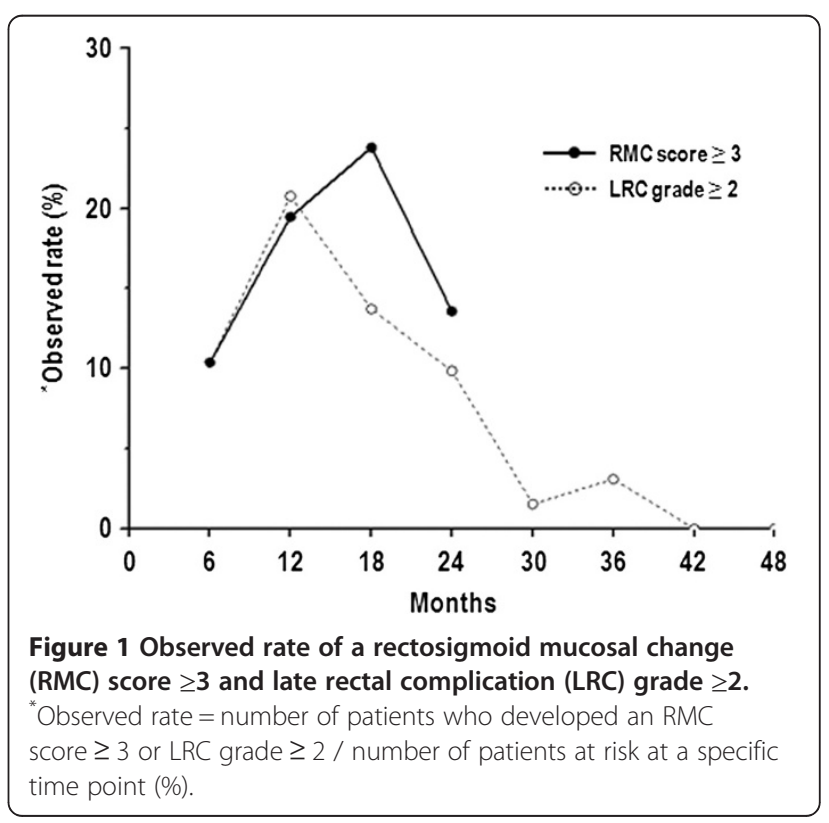




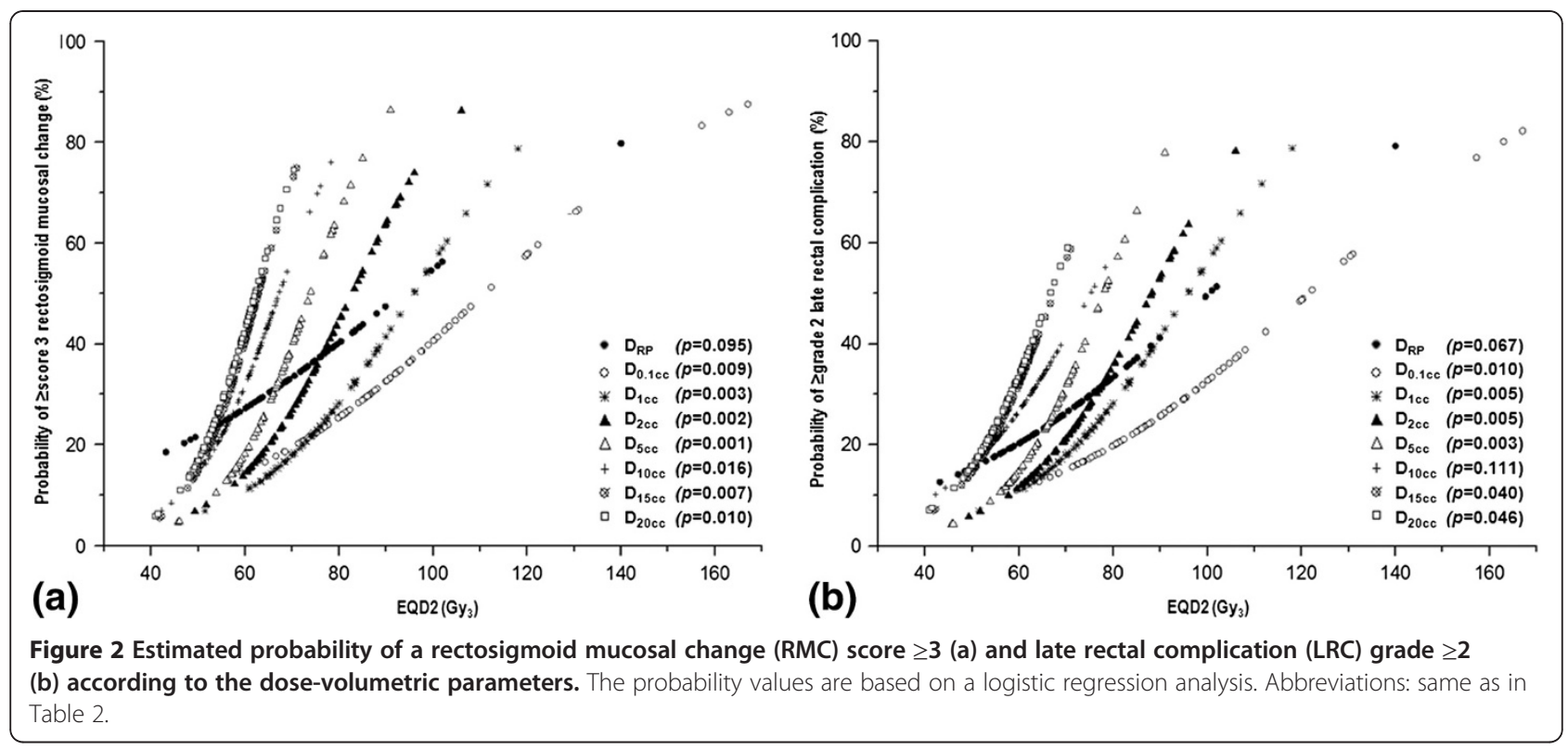

Table 2 Cumulative incidence of a rectosigmoid mucosal change (RMC) score $\geq 3$ and late rectal complication (LRC) grade $\geq \mathbf{2}$ in relation to various dose-volumetric parameters receiving three different dose subgroups

\begin{tabular}{|c|c|c|c|c|c|}
\hline Parameters & & Incidence ${ }^{*}$ of $\geq$ score 3 RMC & ${ }^{t} p$-value & Incidence* of $\geq$ grade 2 LRC & ${ }^{\dagger} p$-value \\
\hline \multirow[t]{3}{*}{$\mathrm{D}_{\mathrm{RP}}\left(\mathrm{Gy}_{3}\right)$} & $<65$ & $8 / 25(32.0)$ & 0.260 & $7 / 25(28.0)$ & 0.070 \\
\hline & $65-74.9$ & $7 / 27(25.9)$ & & $4 / 27(14.8)$ & \\
\hline & $\geq 75$ & $12 / 25(48.0)$ & & $11 / 25(44.0)$ & \\
\hline \multirow[t]{3}{*}{$D_{0.1 c c}\left(G y_{3}\right)$} & $<80$ & $4 / 19(21.1)$ & 0.046 & $2 / 19(10.5)$ & 0.066 \\
\hline & $80-94.9$ & $9 / 32(28.1)$ & & $9 / 32(28.1)$ & \\
\hline & $\geq 95$ & $14 / 26(53.9)$ & & $11 / 26(42.3)$ & \\
\hline \multirow[t]{3}{*}{$D_{1 c c}\left(G y_{3}\right)$} & $<75$ & $8 / 36(22.2)$ & 0.021 & $6 / 36(16.7)$ & 0.021 \\
\hline & $75-89.9$ & 10/27 (37.0) & & 8/27 (29.6) & \\
\hline & $\geq 90$ & $9 / 14(64.3)$ & & $8 / 14(57.1)$ & \\
\hline \multirow[t]{3}{*}{$D_{2 c c}\left(G y_{3}\right)$} & $<70$ & $5 / 30(16.7)$ & 0.010 & 4/30 (13.3) & 0.041 \\
\hline & $70-84.9$ & 10/26 (38.5) & & $9 / 26(34.6)$ & \\
\hline & $\geq 85$ & $12 / 21(57.1)$ & & $9 / 21(42.9)$ & \\
\hline \multirow[t]{3}{*}{$D_{5 c c}\left(G y_{3}\right)$} & $<65$ & 4/31(12.9) & 0.002 & 3/31 (9.7) & 0.002 \\
\hline & $65-74.9$ & $13 / 30(43.3)$ & & 10/30 (33.3) & \\
\hline & $\geq 75$ & $10 / 16(62.5)$ & & 9/16 (56.3) & \\
\hline \multirow[t]{3}{*}{$\mathrm{D}_{10 \mathrm{cc}}\left(\mathrm{Gy} \mathrm{y}_{3}\right)$} & $<60$ & 6/32 (18.8) & 0.017 & $5 / 32(15.6)$ & 0.082 \\
\hline & $60-64.9$ & 10/26 (38.5) & & $9 / 26(34.6)$ & \\
\hline & $\geq 65$ & $11 / 19$ (57.9) & & $8 / 19(42.1)$ & \\
\hline \multirow[t]{3}{*}{$D_{15 c c}\left(G y_{3}\right)$} & $<55$ & 4/28 (14.3) & 0.006 & 4/28 (14.3) & 0.036 \\
\hline & 55-59.9 & $6 / 17(35.3)$ & & $4 / 17(23.5)$ & \\
\hline & $\geq 60$ & $17 / 32(53.1)$ & & 14/32 (43.8) & \\
\hline \multirow[t]{3}{*}{$D_{20 c c}\left(G y_{3}\right)$} & $<55$ & $5 / 30(16.7)$ & 0.011 & $5 / 30(16.7)$ & 0.092 \\
\hline & 55-59.9 & $8 / 22(36.4)$ & & $6 / 22(27.3)$ & \\
\hline & $\geq 60$ & $14 / 25(56.0)$ & & 11/25 (44.0) & \\
\hline
\end{tabular}

Abbreviations: same as in Table 2.

${ }^{*}$ Cumulative incidence $=$ number of patients who developed an RMC score $\geq 3$ or LRC grade $\geq 2$ / number of patients at risk (\%) during follow-up.

${ }^{\dagger}$ Fisher's exact test. 


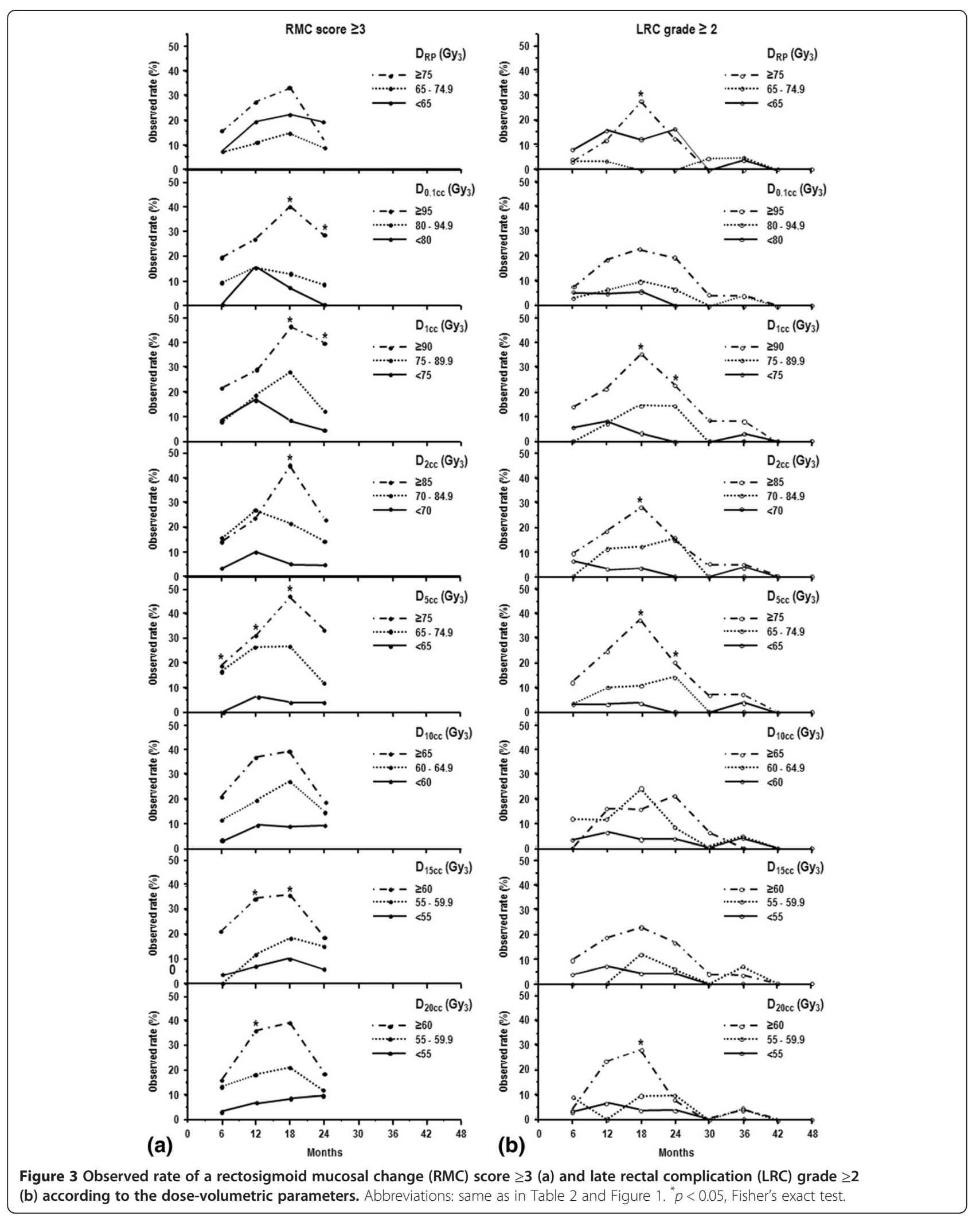


Table 3 Multivariate analysis of factors influencing a rectosigmoid mucosal change (RMC) score $\geq 3$ and late rectal complication (LRC) grade $\geq 2$

\begin{tabular}{|c|c|c|c|c|c|c|c|}
\hline \multirow[b]{2}{*}{ Factor } & & \multirow[b]{2}{*}{ Odd Ratio } & \multicolumn{2}{|l|}{ RMC } & \multirow[b]{2}{*}{ Odd Ratio } & \multicolumn{2}{|l|}{ LRC } \\
\hline & & & $95 \% \mathrm{Cl}$ & $p$-value ${ }^{*}$ & & $95 \% \mathrm{Cl}$ & $p$-value \\
\hline \multirow[t]{2}{*}{ Age (years) } & $\leq 60$ & 1.000 & - & 0.008 & - & - & NS \\
\hline & $>60$ & 21.200 & 2.233-201.247 & & - & - & \\
\hline \multirow[t]{2}{*}{ Stage } & $\mid \mathrm{B}-\| \mathrm{A}$ & 1.000 & - & 0.006 & 1.000 & - & 0.017 \\
\hline & $\|B-\||| B$ & 24.084 & $2.543-228.124$ & & 5.426 & $1.359-21.657$ & \\
\hline \multirow[t]{3}{*}{$D_{5 c c}\left(G y_{3}\right)$} & $<65$ & 1.000 & - & 0.013 & 1.000 & - & 0.031 \\
\hline & $65-74.9$ & 22.426 & $2.329-215.962$ & & 4.222 & $0.976-18.259$ & \\
\hline & $\geq 75$ & 31.103 & $3.084-313.657$ & & 8.528 & $1.710-42.544$ & \\
\hline
\end{tabular}

Abbreviations: $\mathrm{Cl}=$ confidence interval; NS = not significant; the others abbreviations are as in Table 2.

${ }^{*}$ Multivariate logistic regression analysis.

parameters are depicted in Figure $2 \mathrm{a}$ and b, respectively. The probability curves of all dose-volumetric parameters, except in $D_{R B}$ had a statistical significance and the range of radiation dose in the probability curve was smallest for $\mathrm{D}_{20 \mathrm{cc}}$ and greatest for $\mathrm{D}_{0.1 \mathrm{cc}}$. We chose two individual cutoff points for each dose-volumetric parameter considering similar size among the subgroups and changes in the curve gradients and then evaluated the effects of the dose-volumetric parameters on the risk of $\mathrm{RMC} \geq$ score 3 and $\mathrm{LRC} \geq$ grade 2 (Table 2). The cumulative incidence of $\mathrm{RMC} \geq$ score 3 was significantly different among the subgroups according to $\mathrm{D}_{0.1 \mathrm{cc}}, \mathrm{D}_{1 \mathrm{cc}}$, $\mathrm{D}_{2 \mathrm{cc}}, \mathrm{D}_{5 \mathrm{cc}}, \mathrm{D}_{10 \mathrm{cc}}, \mathrm{D}_{15 \mathrm{cc}}$, and $\mathrm{D}_{20 \mathrm{cc}}(p<0.05)$, in contrast to those according to $\mathrm{D}_{\mathrm{RP}}(p>0.05)$. The cumulative incidence of $\mathrm{LRC} \geq$ grade 2 was significantly different among the subgroups according to $\mathrm{D}_{1 \mathrm{cc}}, \mathrm{D}_{2 \mathrm{cc}}, \mathrm{D}_{5 \mathrm{cc}}$, and $\mathrm{D}_{15 \mathrm{cc}}$, in contrast to those in subgroups according to the $\mathrm{D}_{\mathrm{RB}}, \mathrm{D}_{0.1 \mathrm{cc}}, \mathrm{D}_{10 \mathrm{cc}}$, and $\mathrm{D}_{20 \mathrm{cc}}(p>0.05)$. The observed rate of $\mathrm{RMC} \geq$ score 3 and LRC $\geq$ grade 2 , at every 6 month intervals, according to dose-volumetric parameters are depicted in Figure $3 a$ and $b$, respectively. With increasing the dose-volumetric parameters, both RMC $\geq$ score 3 and $\mathrm{LRC} \geq$ grade 2 rates showed an increasing trend, with those differences being the most prominent at 18 months (Figure 3). In multivariate analysis with all clinical and dose-volumetric parameters, $D_{5 \mathrm{cc}}$ remained as a significant factor than other dose-volumetric parameters for the risk of $\mathrm{RMC} \geq$ score $3(p<0.05)$ and the risk of LRC $\geq$ grade 2 along with age and stage, and age, respectively $(p<0.05)$ (Table 3$)$.

\section{Discussion}

The $\mathrm{D}_{\mathrm{RP}} \mathrm{RP}$ ratio $\left(\mathrm{D}_{\mathrm{RP}} / \mathrm{D}_{\text {Point } \mathrm{A}}\right)$, and maximal rectal point dose were used to evaluate the risk of LRC traditionally [11,13-17]. We previously showed that the biologically effective dose at the ICRU rectal point ( $\leq 125$ vs. $>125 \mathrm{~Gy}_{3}$ ) calculated at the orthogonal film-based brachytherapy was equivalent to an EQD2 of $75 \mathrm{~Gy}_{3}$, and was significantly associated with a 5-year actual risk of an LRC grade $\geq 2$
(5.4 vs. 36.1\%; $p<0.001$ ) [11]. Starting with the 3D CTbased brachytherapy in 2004, a prospective observational study was designed to estimate the value of dose-volume parameters in predicting the risk of RMC and LRC. Our preliminary analysis showed that several dose-volumetric parameters $\left(D_{0.1 \mathrm{cc}}, \mathrm{D}_{1 \mathrm{cc}}, \mathrm{D}_{2 \mathrm{cc}}\right.$, and $\left.\mathrm{D}_{\mathrm{RP}}\right)$ were significantly associated with the risk of an RMC $\geq$ score 2 at 12 months [8]. As a continuum study with longer follow-up time, the present data demonstrated close correlations among RMC, LRC, and dose-volumetric parameters. Our data also suggests that $D_{5 c c}$ may be a more reliable estimate than other dose-volumetric parameters for predicting the risk of an RMC $\geq$ score 3 and $L R C \geq$ grade 2 .

Conceptually, dose wall histograms (DWHs) are potentially more valuable than DVHs in determining radiobiological effects on tubular structures. However, it is difficult to obtain DWHs in clinical practice because of the major uncertainties which may result from the very small dimensions of the organs and the inability to have automatically-generated second contours at selected distances by the treatment planning system. Thus, it was allowed to obtain DVHs for the rectosigmoid colon using an external organ contouring method in the GECESTRO recommendations [2]. Apart from the contouring method of OAR, several previous data have demonstrated that doses for $\leq 2 \mathrm{cc}$ volume of rectum (i.e., $\mathrm{D}_{2 \mathrm{cc}}, \mathrm{D}_{1 \mathrm{cc}}$, and $\left.\mathrm{D}_{0.1 \mathrm{cc}}\right)$ is a reliable and consistent factors for predicting the risk of LRC rather than those for $\geq 5 \mathrm{cc}$ volume of rectum (i.e., $\mathrm{D}_{5 \mathrm{cc}}$, and $\mathrm{D}_{10 \mathrm{cc}}$ ) $[4,18]$. On this background, GEC-ESTRO has recommended that $\mathrm{D}_{2 \mathrm{cc}}, \mathrm{D}_{1 \mathrm{cc}}, \mathrm{D}_{0.1 \mathrm{cc}}$, and $D_{R P}$ are mandatory for dose report for OAR [1-5], but the report on the $D_{5 c c}$ and $D_{10 c c}$ was left optional. There is a paucity of study which examined the value of $D_{5 c c}$ for predicting the risk of LRC since the guideline was set up by GEC-ESTRO.

There are several suggestions which may aid in support our result that $D_{5 c c}$ was shown to be the most powerful factor predicting both RMC and LRC. First, the rectum is quite often located asymmetrically or 
deviated to perpendicular line from the cervical os and ICR applicator, and the dose to the smaller volume can over- or underestimate the maximal dose of the rectum as the point doses do in this situation [4]. Second, dosevolumetric parameters have inherent uncertainties from interfractional setup variability of the ICR applicator and the position of the hollow organs in relation to the changes of tumor volumes over time. In Vienna University, the patients were asked to empty rectosigmoid colon before ICR and 3D image-based treatment planning was performed at every ICR fraction for four fractions $[4,5,19]$, whereas in our institute, bowel emptying was not a requirement before ICR and 3D image-based treatment planning was performed only once under the assumption that the dose-volume parameters calculated from an initial ICR plan was the same throughout the rest of procedures. Our practice pattern could have provided higher chance of interfractional variability than the Vienna's one. This is a limitation of our study and thus the interpretation and comparison of our data with other studies in the literatures should be careful. However, our data could be valuable reference for the institutes where fractionated regimen is used on outpatient basis and 3D brachytherapy plan cannot be performed at every treatment session.

One of the caveats of our study is that only $63.6 \%$ of the patients completed all 4 examinations although our study intended 4 rectosigmoidoscopic examinations every 6 months for the first 2 years; the rest (36.4\%) completed only $2-3$ examinations. Although $80 \%$ of the LRC occurred within 24 months, there is about $20 \%(n=7)$ of the LRC events still developed after 24 months (range, 25 50 months). This may raise questions that our 2-year RMC data may not enough to predict the risk for LRC. However, this does not seem to be the case because both RMC and LRC scores showed a consistent time pattern with the peak of the worst score develops at 18 months post-RT and then declines (Figure 3). Ippolito et al. [20] showed that RMC using rectosigmoidoscopy at 1 year after completion of RT in 101 prostate cancer patients had a good positive correlation with clinical LRC, suggesting that RMC of high grade precedes clinical rectal bleeding, which most commonly occurs at $1 \sim 2$ years post-radiotherapy. Georg et al. [5] also showed that most significant RMC matches to the area of the highest radiation dose in 35 cervical cancer patients, however, it could not be elucidated in that study at what time point is the rectosigmoidoscopy most effective in predicting LRC because of the variable time of the endoscopic examination. Our present study shows that the most severe degree of RMC occurs at 18 months post-RT, which is probably the same time point of the median time of development of LRC (15 month in our series). From our and others' results $[8,20]$, post-RT 24 month may be an enough time to predict most of the events of LRC.
There are controversial results in which the risk of LRC could be influenced by various clinical parameters, such as age, diabetes, hypertension, smoking, and stage [14,21-24]. Multivariate analysis of the present study showed that both age and stage was significantly associated with the risk of RMC and LRC, respectively (Table 3), but no association was detected between the RMC/LRC and other parameters. We consider that this finding may be due to the small patient number of our study, and these parameters still need to be investigated further.

\section{Conclusion}

In conclusion, we showed positive correlations among the examined dose-volumetric parameters, RMC, and LRC and suggested that that $D_{5 \mathrm{cc}}$ might be a more reliable estimate for predicting the risk of RMC $\geq$ score 3 and $L R C \geq$ grade 2 than the other dose-volumetric parameters although $\mathrm{D}_{1 \mathrm{cc}}$ and $D_{2 \mathrm{cc}}$ had also significance for with the risk of RMC and LRC in univariate analysis. Given that CT-based brachytherapy is more assessable technique [25-28] globally than the MRI-based one because of the problems of logistics and resources, our result may be meaningful in clinical practice and should be verified by further studies in broader societies using 3D image-based brachytherapy, especially in the institutes where fractionated regimen is used on outpatient basis.

\section{Additional file}

Additional file 1: Table S1. Mean values of the biological dose for point A, clinical target volume (CTV), and organs at risk. Table S2. Correlation between the rectosigmoid mucosal change (RMC) score and late rectal complication $(\mathrm{LRC})$ grade.

\section{Competing interests}

None of the authors have potential conflicts of interest.

\section{Authors' contributions}

JK and THK are responsible for the study design. JK, THK, DKS, YK, YL, SHM, SSK, and DYK collected the clinical data and drafted the manuscript. THK, YK, and $Y L$ revised the manuscript. DKS and YK collected the pathologic data and analysis. JK, THK, YK, YL, SHM, SSK, and DYK were responsible for the treatment and evaluation of the patients. JK, DYK and THK provided oversight of the analysis of data and reviewing of the manuscript. All authors read and approved the final manuscript.

\section{Acknowledgements}

This work was performed under the clinical protocol scheme of NCCCTS-04099 and was supported by a National Cancer Center Grant (NCC-1110540 and 1241110).

Received: 9 December 2012 Accepted: 20 January 2013

Published: 31 January 2013

\section{References}

1. Kirisits C, Potter R, Lang S, Dimopoulos J, Wachter-Gerstner N, Georg D: Dose and volume parameters for MRI-based treatment planning in intracavitary brachytherapy for cervical cancer. Int J Radiat Oncol Biol Phys 2005, 62:901-911. 
2. Potter R, Haie-Meder C, Van Limbergen E, Barillot I, De Brabandere M, Dimopoulos J, Dumas I, Erickson B, Lang S, Nulens A, et al: Recommendations from gynaecological (GYN) GEC ESTRO working group (II): concepts and terms in 3D image-based treatment planning in cervix cancer brachytherapy-3D dose volume parameters and aspects of 3D image-based anatomy, radiation physics, radiobiology. Radiother Oncol 2006, 78:67-77.

3. van den Bergh $F$, Meertens $H$, Moonen $L$, van Bunningen B, Blom A: The use of a transverse $C T$ image for the estimation of the dose given to the rectum in intracavitary brachytherapy for carcinoma of the cervix. Radiother Oncol 1998, 47:85-90.

4. Wachter-Gerstner N, Wachter S, Reinstadler E, Fellner C, Knocke TH, Wambersie A, Potter R: Bladder and rectum dose defined from MRI based treatment planning for cervix cancer brachytherapy: comparison of dose-volume histograms for organ contours and organ wall, comparison with ICRU rectum and bladder reference point. Radiother Oncol 2003, 68:269-276.

5. Georg P, Kirisits C, Goldner G, Dorr W, Hammer J, Potzi R, Berger D, Dimopoulos J, Georg D, Potter R: Correlation of dose-volume parameters, endoscopic and clinical rectal side effects in cervix cancer patients treated with definitive radiotherapy including MRI-based brachytherapy. Radiother Oncol 2009, 91:173-180.

6. Haie-Meder C, Potter R, Van Limbergen E, Briot E, De Brabandere M, Dimopoulos J, Dumas I, Hellebust TP, Kirisits C, Lang S, et al: Recommendations from Gynaecological (GYN) GEC-ESTRO Working Group (I): concepts and terms in 3D image based 3D treatment planning in cervix cancer brachytherapy with emphasis on MRI assessment of GTV and CTV. Radiother Oncol 2005, 74:235-245.

7. Kang HC, Shin KH, Park SY, Kim JY: 3D CT-based high-dose-rate brachytherapy for cervical cancer: clinical impact on late rectal bleeding and local control. Radiother Oncol 2010, 97:507-513.

8. Koom WS, Sohn DK, Kim JY, Kim JW, Shin KH, Yoon SM, Kim DY, Yoon M, Shin D, Park SY, Cho KH: Computed tomography-based high-dose-rate intracavitary brachytherapy for uterine cervical cancer: preliminary demonstration of correlation between dose-volume parameters and rectal mucosal changes observed by flexible sigmoidoscopy. Int J Radiat Oncol Biol Phys 2007, 68:1446-1454.

9. Joiner MC, Bentzen SM: Time-dose relationships: the linear-quadrantic approach. In Basic clinical radiobiology. 3rd edition. Edited by Steel GG. New York: Oxford University Press; 2003:121-133.

10. Wachter S, Gerstner N, Goldner G, Potzi R, Wambersie A, Potter R: Endoscopic scoring of late rectal mucosal damage after conformal radiotherapy for prostatic carcinoma. Radiother Oncol 2000, 54:11-19.

11. Kim TH, Choi J, Park SY, Lee SH, Lee KC, Yang DS, Shin KH, Cho KH, Lim HS, Kim JY: Dosimetric parameters that predict late rectal complications after curative radiotherapy in patients with uterine cervical carcinoma. Cancer 2005, 104:1304-1311.

12. Lang S, Nulens A, Briot E, Kirisits C, De Brabandere M, Dumas I, Dimopoulos J, Petrow P, Georg D, Van Limbergen E, et al: Intercomparison of treatment concepts for MR image assisted brachytherapy of cervical carcinoma based on GYN GEC-ESTRO recommendations. Radiother Oncol 2006, 78:185-193.

13. Clark BG, Souhami L, Roman TN, Chappell R, Evans MD, Fowler JF: The prediction of late rectal complications in patients treated with high dose-rate brachytherapy for carcinoma of the cervix. Int J Radiat Oncol Biol Phys 1997, 38:989-993.

14. Chen SW, Liang JA, Yang SN, Liu RT, Lin FJ: The prediction of late recta complications following the treatment of uterine cervical cancer by high-dose-rate brachytherapy. Int J Radiat Oncol Biol Phys 2000, 47:955-961.

15. Ogino I, Kitamura T, Okamoto N, Yamasita K, Aikawa Y, Okajima H, Matsubara S: Late rectal complication following high dose rate intracavitary brachytherapy in cancer of the cervix. Int J Radiat Oncol Biol Phys 1995, 31:725-734

16. Perez CA, Fox S, Lockett MA, Grigsby PW, Camel HM, Galakatos A, Kao MS, Williamson J: Impact of dose in outcome of irradiation alone in carcinoma of the uterine cervix: analysis of two different methods. Int J Radiat Oncol Biol Phys 1991, 21:885-898.

17. Nag S, Erickson B, Thomadsen B, Orton C, Demanes JD, Petereit D: The American Brachytherapy Society recommendations for high-dose-rate brachytherapy for carcinoma of the cervix. Int J Radiat Oncol Biol Phys 2000, 48:201-211.

18. Pelloski CE, Palmer M, Chronowski GM, Jhingran A, Horton J, Eifel PJ: Comparison between CT-based volumetric calculations and ICRU reference-point estimates of radiation doses delivered to bladder and rectum during intracavitary radiotherapy for cervical cancer. Int J Radiat Oncol Biol Phys 2005, 62:131-137.

19. Georg P, Lang S, Dimopoulos JC, Dorr W, Sturdza AE, Berger D, Georg D, Kirisits C, Potter R: Dose-volume histogram parameters and late side effects in magnetic resonance image-guided adaptive cervical cancer brachytherapy. Int J Radiat Oncol Biol Phys, 79:356-362.

20. Ippolito E, Deodato F, Macchia G, Massaccesi M, Digesu C, Pirozzi GA, Spera G, Marangi S, Annoscia E, Cilla S, et al: Early radiation-induced mucosal changes evaluated by proctoscopy: Predictive role of dosimetric parameters. Radiother Oncol, 104:103-108.

21. Cetina L, Garcia-Arias A, Uribe Mde J, Candelaria M, Rivera L, Onate-Ocana L, Coronel J, Duenas-Gonzalez A: Concurrent chemoradiation with carboplatin for elderly, diabetic and hypertensive patients with locally advanced cervical cancer. Eur J Gynaecol Oncol 2008, 29:608-612.

22. Eifel PJ, Jhingran A, Bodurka DC, Levenback C, Thames H: Correlation of smoking history and other patient characteristics with major complications of pelvic radiation therapy for cervical cancer. J Clin Oncol 2002, 20:3651-3657.

23. Kapp KS, Stuecklschweiger GF, Kapp DS, Poschauko J, Pickel H, Hackl A Carcinoma of the cervix: analysis of complications after primary external beam radiation and Ir-192 HDR brachytherapy. Radiother Oncol 1997, 42:143-153.

24. Kucera $H$, Enzelsberger $H$, Eppel W, Weghaupt $K$ : The influence of nicotine abuse and diabetes mellitus on the results of primary irradiation in the treatment of carcinoma of the cervix. Cancer 1987, 60:1-4.

25. Krishnatry R, Patel FD, Singh P, Sharma SC, Oinam AS, Shukla AK: CT or MR for image-based brachytherapy in cervical cancer. Jpn J Clin Oncol 2012, 42:309-313.

26. Tan LT, Coles CE, Hart C, Tait E: Clinical impact of computed tomographybased image-guided brachytherapy for cervix cancer using the tandemring applicator - the Addenbrooke's experience. Clin Oncol (R Coll Radiol) 2009, 21:175-182.

27. van Dyk S, Byram D, Bernshaw D: Use of 3D imaging and awareness of GEC-ESTRO recommendations for cervix cancer brachytherapy throughout Australia and New Zealand. J Med Imaging Radiat Oncol 2010, 54:383-387.

28. Viswanathan AN, Dimopoulos J, Kirisits C, Berger D, Potter R: Computed tomography versus magnetic resonance imaging-based contouring in cervical cancer brachytherapy: results of a prospective trial and preliminary guidelines for standardized contours. Int J Radiat Oncol Biol Phys 2007, 68:491-498.

doi:10.1186/1748-717X-8-28

Cite this article as: Kim et al: A prospective observational study with dose volume parameters predicting rectosigmoidoscopic findings and late rectosigmoid bleeding in patients with uterine cervical cancer treated by definitive radiotherapy. Radiation Oncology 2013 8:28.

\section{Submit your next manuscript to BioMed Central and take full advantage of:}

- Convenient online submission

- Thorough peer review

- No space constraints or color figure charges

- Immediate publication on acceptance

- Inclusion in PubMed, CAS, Scopus and Google Scholar

- Research which is freely available for redistribution 